\title{
Guidelines to facilitate self-care among older persons in South Africa
}

\author{
Tinda Rabie*, Hester C. Klopper \\ INSINQ Focus Area, Faculty of Health Sciences, North-West University, Potchefstroom Campus, South Africa
}

\section{A R T I C L E I N F O}

Article history:

Received 20 February 2015

Accepted 26 February 2015

Available online 19 August 2015

Keywords:

Older person

Self-care guidelines

\begin{abstract}
A B S T R A C T
Background: The number of older persons is growing at an alarming rate, yet the South African healthcare sector is not giving this issue the required attention. Moreover, the healthcare sector serves four-fifths of the country's population and primary healthcare (PHC) facilities are overcrowded, and thus professional nurses are prevented from providing sufficient self-care health education to older persons.

Aim: To develop guidelines for the three role players - the public health sector, professional nurse and older person - to facilitate self-care among older persons in South Africa. Design: Quantitative, descriptive, explorative and contextual research design.

Methods: A literature review followed by a self-care assessment of a sample of older persons using the Appraisal of Self-care Agency (ASA-A) and Exercise of Self-care Agency (ESCA) questionnaires which led to the identification of conclusions and self-care deficits.

Results: Based on Menon's psychological health empowerment model, and from the conclusions and self-care deficits, nine self-care guidelines were developed for the public health sector, professional nurses and older persons.

Conclusion: This is the first systematic development of guidelines to facilitate self-care among older persons in South Africa.

Implications for practice: The implementation of the self-care guidelines by the public health sector, professional nurses and older persons will improve the healthcare of older persons at home which will in turn improve their quality of life, reduce unintentional self-neglect, as well as assist in alleviating overcrowding in clinics because unnecessary visits to the clinic will drop.
\end{abstract}

Copyright $\odot$ 2015, The Authors. Production and hosting by Elsevier B.V. on behalf of Johannesburg University. This is an open access article under the CC BY-NC-ND license (http://creativecommons.org/licenses/by-nc-nd/4.0/).

\section{Introduction}

The public healthcare sector serves $83 \%$ of the South African population (Council for Medical Schemes, 2011) for whom PHC facilities form the first level of care. These facilities are burdened by factors such as staff shortages, overcrowding, poor quality of care, long waiting periods (Kruger, Greeff, Watson, \& Fourie, 2009) and increasing healthcare costs. Due to the increase in medical technology and the younger South

\footnotetext{
* Corresponding author. North-West University, School of Nursing Science, South Africa. Tel.: +27 182991719.

E-mail addresses: tinda_rabie@yahoo.com (T. Rabie), klopperhc@gmail.com (H.C. Klopper).

Peer review under responsibility of Johannesburg University. http://dx.doi.org/10.1016/j.hsag.2015.02.005

1025-9848/Copyright () 2015, The Authors. Production and hosting by Elsevier B.V. on behalf of Johannesburg University. This is an open access article under the CC BY-NC-ND license (http://creativecommons.org/licenses/by-nc-nd/4.0/).
} 
African population being affected by a decrease in fertility and HIV/AIDS, South Africa has the most rapidly ageing population in Africa (Wetzels, Harmsen, Van Weel, Grol, \& Wensing, 2007 , p. 3). Moreover, in terms of the Bill of Rights in the Constitution of South Africa each older person has a right to adequate healthcare and access to information (South African Human Rights Commission, 1996). Furthermore, the Older Persons Act 13 of 2006 supports the Constitution of South Africa by mentioning the rights of older persons and, among others, the importance of community-based care which ensures that older persons have the opportunity to stay in their own residences as long as possible (Older Persons Act 13 of 2006, p. 4).

One way of assisting the public health sector to care for the high number of older persons and to also help the older people to stay in their own homes for as long as possible is through health promotion activities focussing on self-care. Self-care refers to the ability of a person to purposefully care for the self (Gibbons, 2006, p. 324). The inability of a person to apply selfcare can lead to unintentional self-neglect which inevitably decreases the quality of life. Therefore, unintentional selfneglect can be reduced or eliminated and quality of life improved if proper guidelines are implemented through selfcare support groups. According to Drageset, Eide, Nygaard, Bondevik, Nortvedt and Natvig (2009, p. 67), support on a social level is vital to assist older persons in maintaining normal functioning and quality of life. When older persons live alone in the community they are less likely to implement any selfcare skills that they have learnt. In this study three main role players were identified which each play an important role in facilitating self-care in older persons - the public health sector, professional nurses, and the older persons themselves. Guidelines which act as rules that provide guidance to facilitate suitable actions (Merriam-Webster Encyclopedia) were thus developed for each of these role players to assist the older person in the application of self-care.

\section{Aim of the study}

The aim of the study was to develop guidelines for the three role players - the public health sector, professional nurses and older persons - to facilitate self-care among older persons in South Africa.

The following objectives guided the research process:

- To conduct a literature review to understand self-care and related constructs from a theoretical perspective.

- To assess self-care among older persons by using the ASAA and ESCA questionnaires.

\section{Significance of the study}

This is the first time that systematic developed self-care guidelines have been developed for assisting the three main role players (public health sector, professional nurses and older persons) in order to facilitate self-care in self-care support groups in South Africa.

\section{Literature review}

Currently the number of older persons is growing rapidly and this population is estimated to continue increasing during the next two or three decades. Globally, there are 600 million people over the age of 60 . The percentage of older persons is expected to more than double from $7.6 \%$ to $16.2 \%$ by 2050 (Transgenerational Organization, 2009). In 2010 the African older population accounted for $3.6 \%$ of the total South African population and this percentage is expected to rise to $4.5 \%$ in 2030 and 10\% in 2050 (Nabalamba \& Chikoko, 2011, p. 2). In 2001, there were 3.3 million persons in South Africa over 60 years of age, which represented $7.5 \%$ of the population (Turok, 2006, p. 1); this number has since increased to $7.7 \%$ (Statistics SA, 2011). Despite this reality, according to Nabalamba and Chikoko (2011), the issue of ageing is not receiving much attention in policy dialogue and is therefore not a priority in budget allocations in South Africa. It thus appears that the older population is not seen as an issue that deserves priority attention in the South African healthcare setting. The neglect of this issue will have an influence on the development and maintenance of geriatric services and facilities (Ntusi \& Ferreira, 2004).

Other factors that negatively affect the care of older persons in PHC facilities are staff shortages, high workloads and overcrowding caused by a high unemployment rate in South Africa (Turok, 2006). As a result of unemployment, four-fifths of South African citizens need to be served by the public health sector (Council for Medical Schemes, 2011). Moreover, older persons do not have the freedom or boldness to discuss their health or healthcare problems with healthcare providers. This state of affairs affects their general knowledge about their health conditions, thus impacting on their quality of life and ability to apply self-care. To make matters worse, according to Bastiaens, Van Royen, Rotar Pavlic, Raposo, and Baker (2007), if older people do not have any knowledge about their healthcare problems, they will not know how to treat or to take care of themselves. Therefore, addressing the issue of self-care in the older person is essential.

The term "self-care" includes the notions of self-care agency (capability and power), self-care agent (the older person) and self-care deficits (limitation in self-care agency). Orem (2001) defines the concept of self-care agency as the capability and power a person has to look after the self. In this study the concept of self-care agency refers to the capability and power of the older person to engage in self-care activities (Callaghan, 2006; Lauder, 2001; Tomey \& Alligood, 2006). According to Trasher (2002, p. 115) a person who has good selfcare agency has the power to make deliberate decisions about self-care. The reason for this is that they are equipped with the necessary knowledge, skills and motivation to apply self-care during decision-making and action-taking. In the context of this study this means the older person is empowered to make autonomous decisions. According to Orem (2001), the self-care agent is an individual with unique needs and capabilities engaging in self-care. Thus the agent (older person engaging in self-care activities) engages in a choice of actions and/or has the power to do so (Orem, 2001; Tomey \& Alligood, 2006; Trasher, 2002). In addition to the notion of 
self-care, there is also the notion of self-care deficit. This type of deficit refers to the limitations in the relationship between the self-care agency (self-care capability and power) and the meeting of therapeutic self-care requisites (Orem, 2001).

Self-care deficits may be complete or partial. A complete self-care deficit refers to a situation where a person is incapable of meeting any therapeutic self-care demands whatsoever, whereas a partial self-care deficit occurs when a person is unable to meet some of the therapeutic self-care demands. In other words, a deficit occurs when one or more self-care requisites within the therapeutic self-care demand are not being met. According to Orem (2001, p. 282), professional nurses' familiarity regarding the degree of self-care deficit broadens after determining the patients' self-care capabilities and restrictions.

Self-care thus consists of a variety of care activities deliberately engaged in to promote physical, mental and emotional health in order to maintain life and prevent disease (Godfrey, Harrison, Lysaght, Lamb, Graham \& Oakley, 2011, p. 3). Gibbons (2006, p. 324) adds that self-care means purposeful management of the self and could be considered deliberate whereas self-neglect is explained by Deyer, Goodwin, PickensPace, Burnett, and Kelly (2007, p. 1671) as the inability to provide goods or services to meet one's own basic needs. According to Gibbons (2006, p. 323), "self-neglect prevalence in the older population will become so significant that a preventative strategy will have to be used". In most cases older persons do not neglect themselves intentionally. This was shown in this study to be one of the self-care deficits. This study also revealed that older persons lack the knowledge and ability to acquire knowledge with regard to health and selfcare (see Table 1). According to Bastiaens et al. (2007, p. 40), older persons want to be involved in taking care of their own health and this can be achieved by promoting health and selfcare through health education in the form of self-care support groups within PHC facilities. Through these actions older persons can be empowered with the necessary knowledge which may be used in autonomous decision-making, and which will lead to a decrease in unintentional self-neglect (Lloyd-Sherlock, 2004).

Self-care is vital and represents a basic level of care that stands in its own right; it is "not a poor and amateuristic placebo for professional service delivery" (Godfrey et al., 2011, p. 6). Therefore, for older persons to apply self-care, self-care skills, knowledge and support systems are necessary. Rana, Wahlin, Lundborg, and Kabir (2009) add that supportive environments are required to facilitate lifestyle changes and, for this reason, support in the form of self-care support groups form a necessary component to facilitate self-care. Without self-care support, older persons living alone within the community will not be motivated to sustain a lifestyle change that facilitates self-care, especially if there is no form of encouragement or reinforcement. According to Macdonald, Rogers, Blakeman, and Bower (2007, p. 192), professional nurses should facilitate self-care support groups. This is an indication of the necessity of empowering the older person through the provision of health education by professional nurses in selfcare support groups with support from the public health sector.
Empowerment is not only the way in which a person reclaims control over life. It also enables the individual to maintain health and manage interactions with the healthcare system and self. According to Hage and Lorensen (2005, p. 237), empowerment assists the older person to make autonomous decisions. According to a systematic review conducted by Wetzels et al. (2007), some older persons' responses to lower levels of participation in medical decisions were that "the layman is not qualified to make decisions". Therefore, many older persons are not empowered to make active, autonomous medical decisions regarding their own self-care regarding health problems, emphasising the importance of self-care support groups. As a result, self-care support groups constitute an important part of the concept of self-care. If there is a lack of support, the older person living in the community is less likely to implement the learnt self-care skills. This is supported by Drageset et al. (2009) who have reported that strategies such as social support not only assist older persons in maintaining normal functioning but are also associated with and imperative for the improvement of quality of life.

According to Hairon (2007) and Macdonald et al. (2007), strategies are necessary to implement self-care. These include establishing self-care support groups, information brochures, self-care training sessions, utilisation of technology, guidelines to enhance self-care, general information in the PHC facility and, lastly, the implementation of awareness-raising policies to facilitate the enhancement of self-care. Moreover, Suter and Suter (2008) point out that selfcare support groups should aim to give older persons information that is organised, chronologically planned, logical and provided in a relaxed manner in order to facilitate older persons' involvement and motivation to take an active role in deciding on and planning self-care. According to Gerson, Dorsey, Berg, and Rose (2004), support in self-care activities improves older persons' daily functioning, as many of them are isolated and feel lonely, and therefore they profit from the support of their peers in the community. The value of the implementation of self-care is evident from the discussion above and therefore the researchers of the current study developed self-care guidelines based on the three elements of Menon's psychological health empowerment model (Menon, 2002).

According to Menon (2002, p. 28), health empowerment is conceptualised as an interactive system of the following three elements:

- Regulatory environment consisting of health policy and systems (in this study the public health sector supplying healthcare to older persons at PHC level)

- Health service providers (in this study the professional nurses)

- Individual community members (in this study the older person)

Fig. 1 provides a schematic indication of the health empowerment model adapted from the model of Menon (2002, p. 31) and shows how the researchers of this study see health empowerment. 


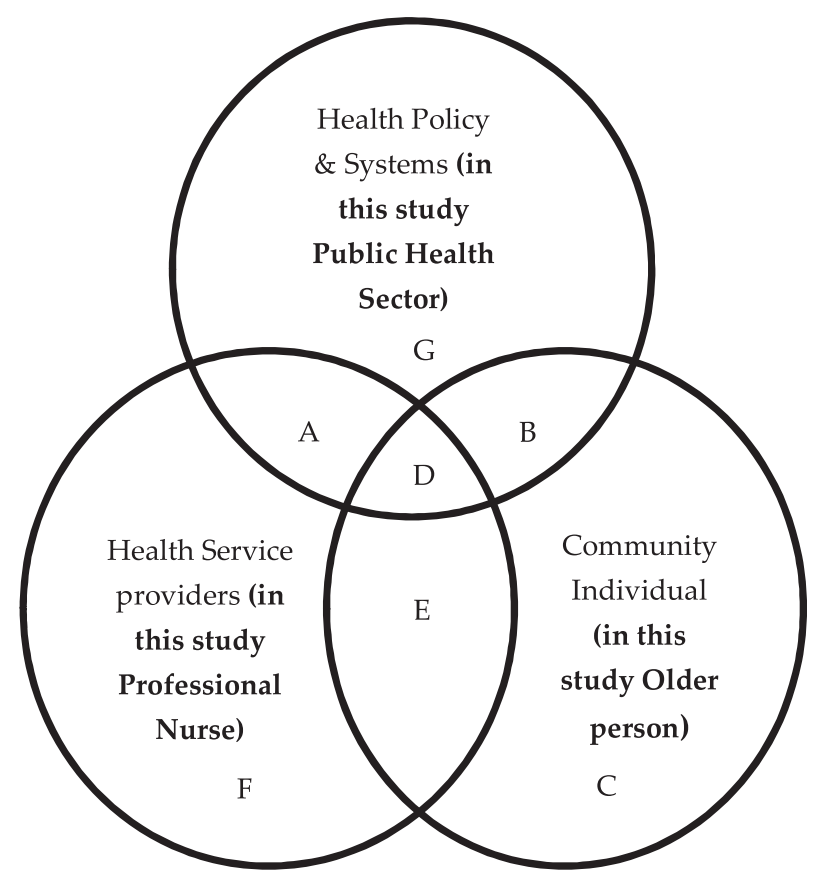

Fig. 1 - Psychological health empowerment model (Adapted from Menon, 2002). Top circle (G): Health Policy \& Systems (i.e. public health sector), Left circle (F): Health Service Providers (i.e. professional nurse), Right circle (C): Community, Individual (i.e. older person).

\subsection{The public health sector}

The public health sector includes regulatory policies and laws regarding health, finances and policy-making bodies and health insurance systems. The government is obliged to provide health services to the public. The public health sector influences the professional nurse and older person directly or indirectly with issues not of immediate concern to the professional nurse or older person (Area G).

The public health sector influences both the professional nurse and older person (see Area D). In Area A, the public health sector, the professional nurse, and in Area B, the older person, are influenced by the public health sector. For example, the public health sector may recommend the abstinence of alcohol or tobacco, and yet the decision to do so still lies with the individual.

\subsection{Professional nurses}

It is not only the professional nurse who is affected by various issues such as reduced staff, overcrowding of PHC facilities and high work demands (Area F). These issues ultimately also affect the older persons who depend on the nurse and entrust their well-being and recovery to the expert in healthcare (Area E). The professional nurse encourages the well-being of the older person by determining and recommending actions that the older person should take in order to take their power back and be in control of their health. The professional nurse in turn expects the older person to adhere to the recommended actions as closely as possible to improve their health.

\subsection{Older persons}

Older persons are the self-care agents who care for their own health, but this may be affected by their individual situation, for example, schooling, life experiences and background, which can influence life and behaviour (Area C). Area E indicates that various issues influence the older person. These issues include health insurance, health education and availability of medical care and professional nurses' interaction with them through health education sessions in self-care support groups. Therefore, healthcare in the older person depends on the professional nurse and public health sector. Thus, the older person is empowered in Areas B, D and E when optimal health is achieved.

\section{Context of the study}

This research study was contextual in nature and conducted in the peri-urban district of Potchefstroom, North-West, South Africa. The study formed part of the Prospective Urban and Rural Epidemiological (PURE) study. To gain a better understanding of the scope of the PURE study of which this study formed a part, a condensed background provided below.

The PURE study's main focus is to examine health changes on non-communicable diseases over a period of 12 years within the Genyesa and Potchefstroom districts. The Genyesa population is referred to as the rural population and the Potchefstroom population as the peri-urban population. The baseline data of the PURE study was collected from August to November 2005. Six thousand randomly selected households were approached to participate in the PURE study. All the participants had to be older than 35 years and volunteered to participate in the study. The criteria for inclusion were as follows: Participants did not use medicine, suffer from any chronic diseases, tuberculosis or HIV/AIDS, or expected a baby or misused alcohol. Sixteen fieldworkers trained to do fieldwork in the communities - eight for the urban population in the peri-urban Potchefstroom district and eight for the rural population in the Genyesa district.

The head of each family signed a voluntary consent form that enabled the fieldworkers to complete the survey. If the family decided not to take part in the study, or there was noone home on the day of the survey, the fieldworkers filled out a non-complier questionnaire and moved to the next residence. After voluntary consent was obtained from the head of the family, the fieldworker informed the participant/s in the family of the purpose of the study and each of the participant/ $\mathrm{s}$ provided their voluntary consent. Participants completed a broad questionnaire which focused on the bio-physical, psychological well-being, socio-economic factors, lifestyle behaviours and support systems. All of the participants who completed the survey were then invited to a research location to perform some tests. Only 1006 of the peri-urban population in the Potchefstroom district and 1015 of the rural population in the Genyesa district underwent the necessary tests. These tests included blood sampling, urine testing, hair sampling, electrocardiographs (ECG), blood pressure measurements and blood glucose testing. After the participants were scrutinised, 
a sub-population of 333 men and women over the age of 60 years who underwent testing as part of the PURE study were identified in both the peri-urban population in the Potchefstroom district (198 individuals) and the rural population in the Genyesa district (135 individuals) (Watson, 2008).

The participating group of the current research study comprised 198 older persons from the peri-urban population in the Potchefstroom district. The participants of this study were characterised by abject poverty and low literacy levels. In total, $72 \%$ of the older persons' main source of income was from monthly government grants; $88 \%$ of the sample had electricity and $72 \%$ had access to water. About half $(55 \%)$ of the studied population had only a primary education and onethird (29\%) had no formal education (Watson, 2008).

\section{Ethical considerations}

Ethical approval Number 04M10 was granted by the NorthWest University Ethical Committee. Before data collection, the fieldworkers provided background information and explained the purpose of the study to the participants in their mother tongue (Setswana). All the participants were informed that their participation was voluntary and that they could withdraw at any time without any penalty. Before the data was collected, the participants gave voluntary consent by either signing or marking the consent form. Care was taken to maintain confidentiality and anonymity of all the information throughout the study.

\section{Research design and method}

\subsection{Research design}

This three-phase study followed a quantitative, descriptive, explorative and contextual design. This was an original design used by the researchers in order to be able to conduct this unique study in South Africa.

\subsubsection{Phase 1}

A literature review on self-care and related constructs was conducted from which a set of conclusions was developed (see Table 1). These conclusions assisted the researchers in summarising the central ideas of a section or theme abbreviated into a single sentence (Anne Arundel Community College).

\subsubsection{Phase 2}

The ASA-A and ESCA questionnaires were employed to assess self-care. Seven self-care deficits were identified. Seven conclusions were derived from these seven self-care deficits (see Table 1).

\subsubsection{Phase 3}

The conclusions derived in the previous two phases formed the basis for generating the self-care guidelines focussing on the public sector, professional nurses and older persons.

\subsection{Research method}

\subsubsection{Phase 1: literature review}

7.2.1.1. Sampling. A literature review was conducted using purposive sampling in order to search for specific constructs (see data collection below) in order to understand self-care and related constructs from a theoretical perspective. Thus, a sample of 118 sources was reviewed.

7.2.1.2. Data collection. In the literature review conducted on self-care and related constructs, the following key words were used to search for relevant information: self-care, including self-care agency, self-care agent, self-care deficit; self-care support groups; older persons (geriatric, elderly, ageing); economic factors (older persons' income, health-care, health care costs); Orem's self-care deficit theory of nursing; unintentional self-neglect; health promotion; empowerment, and quality of life. The search engines used to search for related literature were Medline (1990-2009), PsychINFO (1990-2009), Science Direct (1990-2009), Google, Google Scholar and the CINAHL Database (1990-2009).

7.2.1.3. Data analysis. In order to understand self-care and related constructs from a theoretical perspective, deductive reasoning was used, after which conclusions were drawn (see Table 1).

\subsubsection{Phase 2: self-care assessment}

7.2.2.1. Participants and sampling. The study sample consisted of 198 persons aged 60 and older who lived in private residences. These older persons were a proportion of the older persons who participated in the larger PURE study (Kruger, 2005) and living in the peri-urban Potchefstroom district. Of the 198 questionnaires disseminated, 192 questionnaires were returned, resulting in a $98 \%$ response rate.

7.2.2.2. Data collection. Two existing questionnaires were handed out to the participants, namely the ASA-A (developed by Evers, Isenberg, Philpsen, Senten, \& Brouns, 1993) and the ESCA (developed by Kearny \& Fleischer, 1979), both based on Orem's self-care deficit theory of nursing. Since both the questionnaires seemed fit to achieve the aim of the study, the researchers decided to correlate the two questionnaires as an added objective of the larger study, although the relationship between the two questionnaires is not discussed in this article. Permission to use the questionnaires was obtained from the developers of both questionnaires. These questionnaires had never been tested in South Africa before. Therefore a pilot study was firstly conducted with the assistance of Setswana-speaking fieldworkers who knew the population in order to detect any potential problems that could occur during data collection. After the pilot study minor adaptations were made to the questionnaire. This included translation of the questionnaires into Setswana and changing the original five-point Likert scale into a three-point Likert scale (to make the scale more accessible to the older Setswana-speaking population). The researchers used an expert Setswana translator from the North-West University to assist in translating the English questionnaire into 
Setswana. The questionnaires were translated as during the pilot study the fieldworkers mentioned that the participants would understand the questionnaires better in their mother tongue. After consultation with a statistician at the NorthWest University Statistical Department, the five-point Likert scale was changed to a three-point Likert scale because the majority of the older persons (55\%) in the studied population had no or only primary education and therefore it was easier for them to answer the questions in terms of "agree", "disagree" or "neutral".

Before the fieldworkers began collecting the data, each of the participants was supplied with a letter that explained the background information and contained the ethical approval number of the study. The letter was then explained by the fieldworkers and therafter consent was obtained. The questionnaires were completed by the fieldworkers on behalf of the older persons who were not literate by firstly asking the question and marking the answer provided by the older person.

7.2.2.3. Data analysis. The completed questionnaires were analysed by the Statistical Consultation Services of the NorthWest University, Potchefstroom Campus, and SAS (2003) and SPSS (2008) software was used to interpret the results.

Each item on both the ASA-A and ESCA was marked by the fieldworkers on instruction of the respondents on a threepoint Likert scale. The ASA-A was marked "disagree" (numbered 1), "neither agree nor disagree" (numbered 2) and "agree" (numbered 3), whereas the ESCA was marked in the opposite manner with "very characteristic" (numbered 1), "no opinion" (numbered 2) and "very uncharacteristic" (numbered 3). Both these questionnaires had positively and negatively scored items.

Descriptive statistics were used to examine self-care characteristics and to assess the variable distribution. Descriptive statistics provided the opportunity to arrange the data in such a manner as to be able to understand and give meaning to the phenomenon of self-care from various angles (Burns \& Grove, 2005, p. 461). There are three types of frequency distribution, namely grouped, ungrouped and percentage distribution. The descriptive statistics included percentage distribution. The percentage distribution is employed to describe the percentage of the sample falling into a particular group in this study (Burns \& Grove, 2005, p. 462). The results were presented in tables and percentages using row percentages. Row percentages are cell frequencies expressed as a percentage of the particular row, meaning the percentage distribution of particular answers of each item question (Maree et al., 2008, p. 186).

This enabled the researchers to identify seven self-care deficits which formed part of the conclusions. These selfcare deficits included the older person having a deficit in time management skills; an energy deficit, sleep deprivation deficit; a lack of knowledge and ability to acquire knowledge with regard to health and self-care; a lack of a rest, exercise and self-care programme; physical deterioration, and a lack in the performance of activities to prevent/decrease selfcare deficits (see Table 1). The Cronbach's alpha coefficient of the questionnaires was 0.79 for the ASA-A and 0.79 for the ESCA.

\subsubsection{Phase 3: compilation of self-care guidelines}

Evidence from phases 1 and 2 resulted in 59 conclusions (see Table 1). The conclusions where derived from the literature review conducted (phase 1), and the self-care assessment, which led to the identification of the self-care deficits (phase 2). Thereafter, the researchers used Menon's psychological health empowerment model (see Fig. 1) as a basis to develop guidelines for the three main role players to facilitate self-care among older persons.

\section{Results and discussion}

\subsection{Phase 1}

Based on the literature review conducted on self-care and related constructs, 52 conclusions were developed (see Table 1) which assisted in the systematic development of the guidelines.

\subsection{Phase 2}

Assessment of self-care of the studied population by using the ASA-A and ESCA questionnaires led to the identification of seven self-care deficits from which the researchers derived seven conclusions (see Table 1). These self-care deficits also assisted in the systematic development of guidelines which focus on the older persons affected by abject poverty and low literacy levels in South Africa.

\subsection{Phase 3}

The guidelines were developed based on Menon's psychological health empowerment model (see Fig. 1) which focuses on three main role players, namely the public health sector, professional nurse and older person.

In the following section, three guidelines relating to selfcare of the older persons are formulated for each of the three role players mentioned above. These three role players are interchangeably connected to one another, therefore influencing themselves, one another or both other role players. The nine guidelines developed through deductive logic, as well as recommendations for their implementation (inductive logic), are presented below. The guideline is presented first, followed by the implementation recommendations.

\subsubsection{Public health sector}

The public health sector plays an important role in both healthcare policy development and health promotion. Therefore, this sector should support the older person and especially the professional nurse in the implementation and facilitation of self-care guidelines.

8.3.1.1. Guideline 1. Develop policies to support the facilitation carried out by professional nurses to support older persons in their learning and implementation of self-care provided in self-care support groups. 


\subsection{Implementation recommendations}

- Establish and adapt health policies based on the presentation and implementation of research programmes focussing on self-care among older persons.

- Establish health campaigns to address the lack of performance of self-care activities.

Evidence in support of this guideline: Conclusions 8, 33, 34, $35,36,37,41,46,49,56$ and 59 (see Table 1).

\subsubsection{Guideline 2. Supply resources to implement self-care.}

\subsection{Implementation recommendations}

- Make provision in the budget to appoint and supply professional nurses who can take responsibility for the planning and execution of self-care support groups and selfcare health campaigns.

- Supply environments (venues) for self-care support groups and distribute self-care information brochures.

Evidence in support of this guideline: Conclusions 3, 8, 9, 10, 11, 36, 37, 41, 42, 46, 49 and 56 (see Table 1).

8.3.1.3. Guideline 3. Support professional nurses and older persons participating in the self-care support groups.

\subsection{Implementation recommendations}

- Initiate and support programmes focussing on health promotion of older persons in self-care support groups.

- Launch and support health promotion campaigns facilitated by professional nurses focussing on self-care of older persons in self-care support groups.

Evidence in support of this guideline: Conclusions 3, 4, 8, 9, $10,11,12,16,20,21,22,23,34,35,36,37,41,42,43,44,45,46,49$, 51, 52, 56, 58 and 59 (see Table 1).

\subsubsection{Professional nurses}

The professional nurse has an important role to play in health promotion. In this study, the role is as facilitator of self-care to older persons in self-care support groups. This role empowers the older person to make autonomous decisions, to improve their quality of life and quality of the public health sector because the demand for healthcare and healthcare costs decreases.

8.3.2.1. Guideline 1. Establish, facilitate and support self-care support groups as a health promotion technique to ensure quality of life in older persons.

\subsection{Implementation recommendations}

- Advertise and facilitate self-care support groups for older persons in the clinic.
- Encourage and support self-care in older persons not only in self-care support groups but also during the consultation process.

- Ensure a relaxed and safe environment for the older persons attending the self-care support groups.

- Encourage the older persons to take ownership and comply with self-care skills learnt in self-care support groups.

Evidence in support of this guideline: Conclusions 3, 8, 9, 10, 11, 12, 14, 36, 37, 39, 40, 41, 42, 51, 52 (see Table 1).

8.3.2.2. Guideline 2. Facilitate health education and support older persons to engage in self-care activities to prevent or reduce self-care deficits and to improve quality of life.

8.3.2.2.1. Implementation recommendations. Implement and facilitate health education, and support the older persons with regard to the following:

- Time management skills

- Energy deficit management

- Sleep deprivation management

- Rest, exercise and self-care programmes

- Acceptance of physical deterioration

Evidence in support of this guideline: Conclusions 2, 4, 7, 8, $9,10,11,12,13,14,16,18,19,21,22,25,37,40,41,42,45,48,52$, 53, 54, 55, 57 and 58 (see Table 1).

8.3.2.3. Guideline 3. Attend symposia, conferences and workshops in order to keep up to date with the latest information with regard to care (especially self-care) of older persons.

\subsection{Implementation recommendations}

- Become members of societies and associations supporting older persons.

- Train and encourage other professional nurses on promoting self-care in older persons.

Evidence in support of this guideline: Conclusions 3, 9, 12, 35, 36, 42, 44, 49 and 51 (see Table 1).

\subsubsection{Older persons}

The older person should promote personal health by implementing self-care skills facilitated by professional nurses in self-care support groups. This will not only reduce healthcare demands and healthcare costs for the public health sector, but will also improve the older person's quality of life.

8.3.3.1. Guideline 1. Attend self-care support groups on a continuous basis.

\subsection{Implementation recommendations}

- Communicate with peers regarding the most convenient time during the week to establish self-care support groups.

- Establish individual or communal transport. 
- Attend and encourage peers to attend self-care support groups at scheduled times.

Evidence in support of this guideline: Conclusions 2, 7, 9 , $10,11,12,13,14,19,21,22,37,38,42,44,45,46,49,52$ and 59 (see Table 1).

8.3.3.2. Guideline 2. Implement self-care skills acquired in self-care support groups.

\subsection{Implementation recommendations}

- Establish a rest, exercise and self-care programme to ensure there is time to attend to the acquired self-care skills.

- Establish a buddy system in which peers encourage each other to implement the acquired self-care skills.
Evidence in support of this guideline: Conclusions 2, 4, 5, 6, $12,13,14,19,38,39,42$ and 59 (see Table 1).

8.3.3.3. Guideline 3. Ensure the professional nurse facilitating the self-care support groups is informed about new self-care topics to be addressed.

\subsection{Implementation recommendations}

- Inform professional nurses on self-care deficits and any other topics to be addressed in self-care support groups by continuously keeping a diary of experiences that could contribute to potential self-care topics.

- Place a message box in the self-care support room so that new topics can be suggested.

Evidence in support of this guideline: Conclusions 2, 4, 5, 8, $9,12,13,14,37,38,39,42$, 43, 44, 45, 46, 48, 52 and 56 (see Table 1).

Table 1 - Summary of conclusions (evidence) from the literature review and self-care deficits identified by the ASA-A and ESCA questionnaires.

Conclusions of the literature review conducted

Conclusions regarding self-care

1. Self-care encompasses the concepts self-care agent, self-care agency and self-care deficit.

2. The term self-care means deliberate actions the older persons engage in to maintain health, through disease prevention of disease, assessment of symptoms and reinstatement of optimal health where there is a health limitation.

3. Self-care should be encouraged by professional nurses as self-care forms part of the blueprint of health promotion in community development of lower income countries. It alleviates health care demands and lowers health care costs.

Conclusions regarding self-care agency

4. Self-care agency is the capability and power older persons have to engage in self-care activities and are dependent on the power that older persons have to make deliberate decisions regarding self-care.

5. Capability and power vary according to age, health status, education, life experiences and cultural influences and are developed and managed through learning.

6. The older persons engaging in self-care agency address three types of needs namely universal needs, developmental needs and health deviation needs.

Conclusions regarding self-care agent

7. The self-care agent is the older person engaging in self-care activities.

Conclusions regarding self-care deficit

8. Self-care deficit is present when there is a lack of engagement in self-care requisites, limited awareness of self and environment, a lack of ability to remember past experiences, no ability to make self-care decisions due to a lack of knowledge or unawareness of internal and external circumstances, impaired execution of self-care actions and not having specialised knowledge and skills needed for self-care.

Conclusions regarding self-care support groups

9. Self-care support is a service that professional nurses provide to support and empower the older person by providing health education, small discussions and technology to improve quality of life and self-care.

10. Older persons living in the community are less likely to apply learnt self-care skills if there is no form of support. Therefore, support (in this study in the form of self-care support groups) is imperative for self-care compliance to improvement of quality of life. These groups must be conducted in an organised and relaxed atmosphere in order to alleviate uncertainty and anxiousness regarding health.

11. Professional nurses conducting health education in self-care support groups should give the older persons a sense of security, especially when using the storytelling technique when the older persons' literacy levels are low.

Conclusions regarding Dorothea Orem's self-care deficit theory of nursing

12. The theory of self-care consists of universal, developmental and health deviation self-care. The theory of self-care deficit consists of selfcare deficit and therapeutic self-care demands; and lastly, the theory of nursing systems consists of wholly compensatory, partly compensatory and supportive educative systems.

13. The older person is dependent on self, responsible for self-care and should be encouraged to maintain and take responsibility for his own health.

14. Self-care is a continuous process the older person has to engage in to promote health. Health depends on physical, psychological, interpersonal and social aspects that interrelate with each other in self-care.

Conclusions regarding the older person

Body

15. Each person has a body, mind and spirit. The physical body, strength and health are affected by the ageing process, which could in turn affect the mind and spirit of the older person and vice versa. 


\section{Table 1 - (continued)}

16. Ageing does not only cause "maturation and senescence of biological systems", which means progressive weakening of body systems, but is also a life process that everyone experiences at different time, and for different lengths. Ageing increases the risk of self-care deficits and death as a person ages, because a person is more prone to suffer from chronic disease and physical impairment.

17. Senescence not only causes somatic changes but also economic and health problems which, in turn, causes isolation.

18. Physical deterioration causes functional limitations, which include decreased energy level and sleep deprivation. Energy levels are enhanced by dietary intake and exercise, and sleep deprivation is resolved by exercise and non-drug management interventions.

19. The older person needs exercise, rest and self-care programmes as well as time management skills to effectively care for self.

\section{Mind}

- Social

20. Social support has a very good relationship with quality of life, because social health is subjective to the interrelationship between physical, psychological and social factors.

21. Older persons are affected by retirement, health problems, loss of relatives and friends, causing potential isolation. Therefore, the importance of support given to older persons (in this study through self-care support groups) will have a very important effect on the health of the older persons.

22. Support increases physical and psychological wellbeing as well as health and acceptance of circumstances, enabling the older persons to have a positive outlook on life.

- Psychological

23. Psychological wellbeing of the older persons and social support for the older persons positively influence physical health; increasing quality of life.

24. Ageing has a psychological effect on older persons, because older persons are subjected to retirement, decreased income, changes in social relationships, physical body and health changes as well as the death of loved ones.

25. Acceptance is linked to psychological health, because acceptance leads to positive thought and allows a person to enjoy different experiences. Therefore, the older persons should be taught to accept ageing and its accompanying factors.

Spiritual

26. There is a strong relationship between psychosocial and physical health, and spiritual commitment in the older persons, because the older persons become more active in spiritual activities, as spiritual activities support coping.

27. Spiritual growth influences the older persons' self-care agency (self-care capability and power), since older persons who are routinely involved in spiritual practices, have better initiative and responsibility to care for the self.

28. Spiritual actions and attitudes are associated with social support (in this study self-care support groups). Spirituality increase psychological and physical health to an extent. Therefore, religion is a very important coping mechanism and prime motivational aspect in older persons' lives.

Conclusions on the older persons income

29. The majority of older persons in South Africa are dependent on the social grant of the state called old-age pension, which is not sufficient for the older persons to care for self. The large number of older persons depending on this social grant is due to high unemployment rates, illiteracy as well as poor employment opportunities of the older persons as young adults.

30. High demand on older persons' income is due poor income, high cost of old-age homes, and many older persons that act as caregivers for children, making an average of three persons dependent on the old-age pension.

31. The social health system, with reference to old-age pension, is influenced by corruption, incompetent staff at pay-out points, poor facilities, security and theft influencing the channels of pension money contributed to older persons.

Conclusions regarding health care costs

32. Older persons have three options in health care namely, PHC, private practitioners and hospitals (private or public).

33. South Africa has two types of funding and provision environments, namely the private sector that serves $17 \%$ of the population and the public sector serving $83 \%$ of the population.

34. The lower a person's income the more likely self-care is applied; therefore, self-care should be especially implemented in lower income groups as a strategy to ensure quality of life.

35. The health care system needs to change by supporting autonomy in older persons, which will result in a decrease in the professional help needed.

Conclusions regarding unintentional self-neglect

36. Although professional nurses are confronted by unintentional self-neglect of older persons on a continuous basis, little is done at PHC level to communicate and organise application of self-care.

37. Older persons do not have knowledge about their conditions to make self-care decisions. They only have a primary level of education, which disables them to search, find and read information about self-care. This in turn might lead to unintentional self-neglect.

38. Older persons only do not have knowledge about their conditions to make self-care decisions, and only have primary level of education, disabling them to search, find and read information about self-care, causing potential unintentional self-neglect.

Conclusions regarding health promotion

39. Health promotion is defined as a course of actions undertaken to enable individuals to promote health on a body, mind and spiritual level

40. Health promotion is seen as a concept in practice and health education as the strategy and basis for health promotion in lower socioeconomic communities.

41. Health education does not take place due to, limited education, time restrictions, limited resources, support and the non-existence of clear policies regarding health promotion.

42. Professional nurses are in the best position to empower and promote health, since the teach self-care to older persons. Professional nurses should encourage the older person to use the "bottom-up" approach.

Conclusions regarding empowerment 


\section{Table 1 - (continued)}

43. Health is promoted through empowerment, as it provides the older persons self-confidence and power to control their health.

44. Empowerment is achieved when professional nurses provides information and skills, to older persons enabling them to make autonomous decisions.

45. Health education is a form of empowerment and contributes to autonomy, as a person is able to participate knowingly in decisions regarding self-care.

46. Menon's model of psychological health empowerment (as adapted for this study) has three interactive elements namely, the public health sector, professional nurses and older persons.

Conclusions regarding autonomy

47. Autonomy means independence in decision-making regarding self-care and independence is compromised when there are limitations in autonomy.

48. When there is a limitation in autonomy due to a lack of knowledge, the professional nurse should increase autonomy through health education in self-care support groups.

49. The older persons have a right to information, in order to make autonomous decisions regarding self-care, health and treatment. Many older persons have limited knowledge about their rights and entitlements regarding health care and should therefore become more aware of their rights to participate autonomously in health and self-care decision-making.

Conclusions regarding quality of life

50. Quality of life is an indefinable, personal perception of a person's lived experience as well as its quality.

51. The ultimate goal of nursing is to enhance quality of life in a holistic way.

52. Quality of life as well as life expectancy is enhanced through the improvement of/and promotion of health; empowering the older persons by means of health education on self-care strengthens it.

Conclusions of identified self-care deficits identified after data analysis of the ASA-A and ESCA questionnaires

53. The older person has a deficit in time management skills, affecting self-care.

(ASA-A: Items 20 and 23

ESCA: Items 20 and 25)

54. The older person has energy deficit, affecting self-care.

(ASA-A: Items 6, 9 and 13

ESCA: Items 3, 15 and 37)

55. The older person has a sleep deprivation deficit.

(ASA-A: Items 6 and 13

ESCA: Item 3)

56. The older person has a lack of knowledge and ability to acquire knowledge with regard to health and self-care.

(ASA-A: Items 2, 5, 14 and 15 (Lack of knowledge)

ASA-A: Items 14, 15, 16, 21 and 22 (Lack of ability to acquire knowledge)

ESCA: Items13, 24, 28 and 35 (Lack of knowledge)

ESCA: Items 4, 8, 17, 19, 22 and 40 (Lack of ability to acquire knowledge))

57. The older person has a lack of a rest, exercise and self-care programme.

(ASA-A: Items 11, 13 and 19

ESCA: Items 25 and 29)

58. The older person has a self-care deficit caused by physical deterioration.

(ASA-A: Items 3 and 24

ESCA: 0 items)

59. The older person experiences a lack in the performance of activities to prevent/decrease self-care deficits.

(ASA-A: Items 1, 7, 9, 17, 18, 19 and 22

ESCA: Items 5, 6, 8, 10, 13, 15, 16, 17, 19, 22, 25, 28, 30, 33, 38, 39, 40 and 42)

\section{Recommendations}

Based on the findings of this study, the effective implementation and commitment in the execution of the guidelines developed have the potential to yield maximum benefits for all three main role players in facilitating self-care among older persons.

\section{Limitations of this study}

The PURE study only included a proportion of the older persons in the peri-urban district of Potchefstroom and thus these guidelines may merely serve as a guide in terms of the greater older population. 


\section{Conclusion}

A quantitative study was conducted using an exploratory, descriptive and contextual design in different phases. The study aimed to address the application of self-care in older persons by three main role players, namely the public health sector, professional nurses and older persons by means of self-care support groups.

The public health sector serves most of the South African population and is therefore faced with various challenges which affect the quality of care given to older persons with regard to health education focussing on self-care. The implementation of the developed guidelines could be beneficial since these guidelines focus not only on empowering the older person in preventing self-neglect, ensuring quality of life and functional independence, but also focus on assisting the professional nurse and the public health sector. The professional nurse is faced with overcrowding in PHC facilities and increased workloads, and the public healthcare sector can deal with these issues through policy development, health promotion activities focussing on older persons and alleviating overall healthcare costs.

\section{Recommendations for further research}

Based on the literature review, the research findings and conclusions drawn from this research, it is evident that further research in the field of self-care of older persons is urgently required. Future studies could examine the following issues in more detail:

- The effect of self-care support groups on self-care of the older person

- Self-care practices of older persons in different cultures

- The perceptions of professional nurses regarding the available support systems in the workplace when dealing with older persons

- The level of commitment of older persons to attend selfcare support groups and the application of their acquired self-care skills

- The level of commitment of the professional nurse in the facilitation of self-care support groups

\section{Acknowledgements}

The authors would like to thank all supporting staff and the participants of the PURE South Africa study and in particular the following:

1. The PURE SA research team and in particular Prof Annamarie Kruger who is the principle investigator and coordinator of the South African leg of PURE; Dr Mada Watson who was responsible for the gerontological data used in this study; field workers and office staff in the Africa Unit for Transdisciplinary Health Research (AUTHOR); and the Faculty of Health Sciences, North-West University, Potchefstroom (South Africa).
2. Funders of the PURE SA study: SANPAD (South Africa-Netherlands Research Programme on Alternatives in Development), South African National Research Foundation (NRF GUN numbers 2069139 and FA2006040700010), NorthWest University, the Population Health Research Institute in Ontario, Canada, and the Medical Research Council of SA.

\section{R E F E R E N C E S}

Bastiaens, H., Van Royen, P., Rotar Pavlic, D., Raposo, V., \& Baker, R. (2007). Older people's preferences for involvement in their own care: a qualitative study in primary health care in 11 European countries. Patient Education and Counselling, 68, $33-42$.

Burns, N., \& Grove, S. N. (2005). The practice of nursing research conduct: Critique and utilization (5th ed.). St. Louis, MO: Elsevier (USA.

Callaghan, D. (2006). The influence of growth on spiritual self-care agency in an older adult population. Journal of Gerontological Nursing, 43-51. September.

Council for Medical Schemes. (2011). Annual report 2010/11. Pretoria, SA: Council for Medical Schemes.

Deyer, C. B., Goodwin, J. S., Pickens-Pace, S., Burnett, J., \& Kelly, P. A. (2007). Self-neglect among the elderly: a model based on more than 500 patients seen by a geriatric medicine team. American Journal of Public Health, 97(9), 1671-1676.

Drageset, J., Eide, G. E., Nygaard, H. A., Bondevik, M., Nortvedt, M. W., \& Natvig, G. K. (2009). The impact of social support and sense of coherence on health-related quality of life among nursing home residents - a questionnaire survey in Bergen, Norway. International Journal of Nursing Studies, 46, $66-76$.

Evers, G. C. C., Isenberg, M. A., Philpsen, H., Senten, M., \& Brouns, G. (1993). Validity testing of Dutch translation of the appraisal of self-care agency A.S.A.-Scale. International Journal for Nursing Studies, 30(4), 331-342.

Gerson, L. D., Dorsey, C., Berg, J., \& Rose, E. (2004). Enhancing selfcare in community-dwelling older adults. Geriatric Nursing, 25(5), 272-276.

Gibbons, S. (2006). Primary care assessment of older adults with self-care challenges. The Journal for Nurse Practitioners, 2(5), 323-328.

Godfrey, C. M., Harrison, M. B., Lysaght, R., Lamb, M., Graham, I. D., \& Oakley, P. (2011). Care of self-care by other, care of other: the meaning of self-care from research, practice, policy and industry perspectives. International Journal of Evidence-based Healthcare, 9, 3-24.

Hage, A. M., \& Lorensen, M. (2005). A philosophical analysis of the concept empowerment: the fundament of an educationprogramme to the frail elderly. Nursing Philosophy, 6, 235-246.

Hairon, N. (2007). Evidence on effectiveness of self-care support strategies. Nursing Times, 103(49), 21-22.

Kearny, B. Y., \& Fleischer, B. J. (1979). Development of an instrument to measure exercise of self-care agencies. Research in Nursing Health, 2(1), 25-34.

Kruger, A. (2005). Prospective urban and rural epidemiological study (PURE): Instruction manual for South Africa (2nd draft). Potchefstroom: North-West University.

Kruger, A., Greeff, M., Watson, M. J., \& Fourie, C. M. T. (2009) Health care seeking behaviour of newly diagnosed HIV infected people from rural and urban communities in the North West Province of South Africa. Africa Journal of Nursing and Midwifery, 11(2), 30-47.

Lauder, W. (2001). A survey of self-neglect in patients living in the community. Journal of Clinical Nursing, 8, 95-102. 
Lloyd-Sherlock, P. (2004). Primary health care and older people in the South: a forgotten issue. The European Journal of Development Research, 16(2), 283-300.

Macdonald, W., Rogers, A., Blakeman, T., \& Bower, P. (2007). Practice nurses and the facilitation of self-management in primary care. Journal of Advanced Nursing, 62(2), 191-199.

Maree, K., Creswell, J. W., Ebersöhn, L., Ferreira, R., Ivankova, N. V., Jansen, J. D., et al. (2008). First steps in research. Pretoria: Van Schaik.

Menon, S. T. (2002). Toward a model of psychological health empowerment: implications for health care in multicultural communities. Nurse Education Today, 22, 28-39.

Merriam-Webster. An encyclopaedia Britannica company. Retrieved from http://www.merriam-webster.com/dictionary/ guideline

Nabalamba, A., \& Chikoko, M. (2011). Aging population challenges in Africa. African Development Bank, 1(1), 1-19.

Ntusi, N., \& Ferreira, M. (2004). South African doctors and elderly patients. BOLD, 15(1), 3-13.

Older Persons Act 13 (2006). Retrieved from http://www.justice. gov.za/legislation/acts/2006-013_olderpersons.pdf

Orem, D. E. (2001). Nursing concepts of practice (6th ed.). St. Louis, Missouri: Mosby's Inc.

Rana, A. K. M. M., Wahlin, A., Lundborg, C. S., \& Kabir, Z. N. (2009). Impact of health education on health-related quality of life among elderly persons: Results from a community-based intervention study in rural Bangladesh. Health Promotion International, 24(1), 26-45.

SAS Institute Inc. (2003). The SAS system for Windows Release 9.1 TS Level 1M3. Cary, NC, USA: SAS Institute Inc.. Copyright ${ }^{\oplus}$ by.
South African Human Rights Commission. (1996). Older people, you have rights. Retrieved from http://www.sahrc.org.za/home/21/ files/Leaflet\%20Posters/Elderly.pdf.

SPSS. (2008). Data analysis with comprehensive statistics software. Illinois: SPSS Inc. Headquarters. Retrieved from http://www. spss.com/SPSS/.

Statistics South Africa. (2011). Midyear population Estimates. Retrieved from http://www.statssa.gov.za/publications/P0302/ P03022011.pdf.

Suter, P. M., \& Suter, W. M. N. (2008). Timeless principles of learning: a solid foundation for enhancing chronic disease self-management. Home Health Nurse, 26(2), 82-88.

Tomey, A. M., \& Alligood, M. R. (2006). Nursing theorists and their work (6th ed.). St. Louis, Missouri: Mosby Inc.

Transgenerational Organization. (2009). The demographics of aging. The swelling aging population. Retrieved from http:// transgenerational.org/aging/demographics.htm.

Trasher, C. (2002, March). The primary care nurse practitioner: advocate for self-care. Journal of the American Academy of Nurse Practitioners, 14(3), 113-117.

Turok, M. (2006). South African older persons' forum (Steering committee).

Watson, M. J. (2008). Community-based collaboration to support the older person in the world of HIV/AIDS. Unpublished thesis. Potchefstroom, SA: North-West University.

Wetzels, R., Harmsen, M., Van Weel, C., Grol, R., \& Wensing, M. (2007). Interventions for improving older patients' involvement in primary care episodes. The Cochrane Collaboration. San Francisco, CA: Wiley. 